\title{
Global Justice and the Motivation to Give
}

\author{
Siyang Liu ${ }^{1}$
}

Received: 26 June 2021 / Accepted: 18 November 2021 / Published online: 6 January 2022

(c) Fudan University 2021

\begin{abstract}
Cosmopolitans, statists and liberal nationalists disagree over the relevance of regulating substantive inequalities at the global level. This paper aims to resolve the dispute among these three schools of thought. I show firstly that cosmopolitans, statists, and liberal nationalists all aim to motivate people to give in support of distributive justice at the global level. However, cosmopolitans lack a substantive theory of how to develop sufficient motivation to give globally. Secondly, the statists' account of the motivation to give is deficient because it fails to recognise the motivational force of a common national identity among people. Thirdly, Miller's account is more plausible than the statists' but fails to facilitate a dynamic process whereby people's national identities could be extended to the global level in order to support the cosmopolitan project. This needs to be supplemented by the statists' understanding of democratic process - one which incorporates the principles of Habermas's communicative action as a mechanism for developing social solidarity among people. I endorse an account that recognises the motivational force of national identity and the possibility of extending it beyond nation state through democratic participation at the global level.
\end{abstract}

Keywords Global justice $\cdot$ Motivation to give $\cdot$ National identity $\cdot$ Altruism

\section{Introduction}

Due to the increasing interconnectedness among nation states since the 1990s, political theorists in the West have started to focus on resolving common normative issues at the global level. One of these issues is how equitably various material resources are distributed among people. Despite developed countries' continuous efforts to assist their developing counterparts, the problems of poverty and radical material inequalities persist. More importantly, even Western scholars seem unable

Siyang Liu

fan1962@yeah.net

1 School of Politics and Public Administration, Southwest University of Political Science and Law, Chongqing, People's Republic of China 
to reach a consensus on what developed countries should do in order to fulfil their moral obligations towards the rest of the world.

In the global justice debate, cosmopolitans, statists, and liberal nationalists have long disagreed about the relevance of the regulation of substantive inequalities at the global level. Cosmopolitans argue that the regulation of substantive inequalities should be extended to the global level, because the arbitrary distinction between domestic and global level is not only unjustifiable on the basis of the moral equality of human beings (Caney 2005, p. 130), but also unacceptable to the global poor whose life prospects are greatly affected by it (Gilabert 2012, p. 10). In contrast, statists and liberal nationalists insist that the regulation of substantive inequalities should be restricted to nation-states, due to the differences between national and global contexts. Statists differ from liberal nationalists in terms of the relevant characteristics which distinguish nation-states from the global realm. They argue that it is only necessary to regulate substantive inequalities among people who come under the jurisdiction of the same administrative state (Nagel 2005; Blake 2013; Sangiovanni 2007). Liberal nationalists believe that the regulation of substantive inequalities should be required among people who share a common national identity and public culture in addition to citizenship of the same state, as this directly affects people's motivation to shoulder moral obligations towards others.

In this paper, I will argue that a plausible account of developing distributive principles should be based on an account of the incentive to give that recognises the motivational force of national identity and the possibility of extending this to the global level through democratic participation at that level. In Sect. 2, I will demonstrate that the disagreement over global distributive justice in fact boils down to their different understanding of the motivation to give. Like statists and liberal nationalists, cosmopolitans believe distributive principles have motivational force. However, they fail to develop a specific enough theory that can explain where the said motivation is derived. In Sect. 3, I will show that the statists' account of the motivation to give is deficient because it fails to recognise the motivational force of people's common national identities. As the statists' account is insufficiently detailed, I will focus in this paper on Habermas's theory of constitutional patriotism, which supports their account. In Sect. 4, I will prove that Miller's account is more plausible than the statists' but fails to facilitate a dynamic process whereby a common identity could be extended to the global level. It therefore needs to be supplemented by Habermas's understanding of the democratic process as the mechanism for realising social solidarity among people.

\section{Cosmopolitans and Their Neglect of Particular Context}

When it comes to discussion of global justice, a distinction between weak and strong strands of cosmopolitan position is quite useful, as it serves to direct our attention to what is really at stake in the debate among cosmopolitans, statists and liberal nationalists over the fairness of global distributive principles. As David Miller conceptualises it, weak cosmopolitanism says that various advantages and disadvantages (including material and nonmaterial matters) accruing to people should be valued 
in the same way regardless of who these people are and where they live in the world (Miller 2007, p. 28). In effect, it requires us to give people equal consideration of some kind when distributing dis-/advantages (especially material resources) globally. This cosmopolitan position echoes Simon Caney's general definition of moral universalism. Moral universalism, he contends, is the belief that some moral values are valid across the world (Caney 2005, p. 26). In the debate over global distributive principles, moral universalism similarly requires that some distributive principles be applied in the same way to people across the world. As Su Gu correctly points out, some kind of universal values is needed to serve as the moral foundation of global distributive justice, otherwise the debate will lack a common standard for evaluating the fairness of the global distributional pattern (Gu 2019, p. 264). In this sense, weak cosmopolitanism is widely accepted by all global justice theorists, insofar as it is almost impossible to advance any claim with regard to the fairness of the global distributional pattern without already assuming the universal force of the claim itself.

On the other hand, a strong strand of cosmopolitanism exists to argue for a substantive equality of some sort among people in the world. Be it equal ownership of natural resources, equal access to certain material goods, equal opportunity, et cetera, the strong strand of cosmopolitanism goes much further than weak cosmopolitanism to require the universal application of certain egalitarian distributive principles globally. In order to justify global egalitarian principles, as Miller contends, strong cosmopolitanism has to substantiate the claim that explains why equal consideration of people necessarily implicates global substantive equality (Miller 2007, p. 30). To date, there have been two argumentative routes for regulating substantive inequality at global level. First, strong cosmopolitanism could claim that people's membership in a nation or his/her citizenship of a state is mere social contingencies whose effect should not be allowed to impact on his/her own distributional outcome. In this sense, equal consideration of people implicates mitigating the impact of nation-states on the people who happen to reside within their territories. Second, strong cosmopolitanism could claim that the interpersonal relationship at global level takes certain form that in and by itself necessitates the regulation of substantive inequalities among people. In this sense, equal consideration implicates matching egalitarian distributive principles with a specific kind of interpersonal relationship at the global level, especially the kind that resembles the relationship among members of the same nation-states (Tan 2019, pp. 255-256). As far as the justifiability of the global egalitarian distributive principles is concerned, neither argumentative route taken by the cosmopolitans has convinced the statist and liberal nationalist theorists. Therefore, despite the general support of the weak cosmopolitan position by all global justice theorists, the strong cosmopolitan position that argues for the regulation of substantive inequalities among all people in the world has been the main point of disagreement among cosmopolitans, statists, and liberal nationalists.

The cosmopolitans' global egalitarian distributive principles have been criticised by statists and liberal nationalists for overlooking the particular distributive context which these principles are intended to regulate. For instance, Walzer argues that 'Morality is thick from the beginning, culturally integrated, fully resonant, and it reveals itself thinly only on special occasions, when moral language 
is turned to specific purposes' (Walzer, 1994, p. 4). He rejects the cosmopolitan tendency to formulate global principles of distributive justice independently of local contexts and then substantiate them further with particular cultural values prevalent within specific distributive contexts. In similar vein, Miller calls cosmopolitanism's tendency to treat contextualist morality as a localised extension of the general and abstract principle, the 'Starship Enterprise view of political philosophy'. According to him, this view is doomed to irrelevance, because,

"It draws a line between political philosophy proper, which involves defining concepts and setting out principles in an entirely fact-free way, and applied political theory, which takes these basic concepts and principles and, in the light of empirical evidence, proposes a more concrete set of rules to govern the arrangements of a particular society, or a particular group of societies" (Miller 2008, p. 31).

When moral reasoning is properly done-what he calls 'political philosophy for earthlings' - 'even the basic concepts and principles of political theory are factdependent' (Miller 2008, p. 31). Therefore, the characteristics of a particular distributive context should be allowed to constrain how we understand the moral demands of distributive justice.

In response to statists' and liberal nationalists' critique, the cosmopolitans argue that moral reasoning about distributive justice should aim to expose the shortfalls of the world as it is, as compared to the world as it should be. This conviction is based on an interpretation of Rawls's notion of 'realist utopia'. Rawls, in The Law of Peoples (1999), memorably coins the notion of a 'realist utopia' to denote the division between the 'ideal' and the 'non-ideal approaches' that jointly serve to bring an ideally desirable vision of social institutions closer to the world as it is within the various constraints posed by particular contexts. Nonetheless, he claims,

"The problem here is that the limits of the possible are not given by the actual, for we can to a greater or lesser extent change political and social institutions and much else. Hence we have to rely on conjecture and speculation, arguing as best we can that the social world we envision is feasible and might actually exist, if not now then at some future time under happier circumstances" (Rawls 1999, p. 12).

Taken at face value, cosmopolitans appear to embrace the Rawlsian commitment to a 'realist utopia'. They accept the contextualisation of moral principles in different non-ideal situations. However, they believe that the facts about the real world as it is should not constrain moral reasoning at the fundamental level, so as to preserve the critical bite of the utopian vision.

Therefore, according to the cosmopolitan view, a fixation on the existing features of the distributive context would only lead to a bias towards the status quo. Valentini gives two versions of the charge of status quo bias against statism and liberal nationalism: the static and the dynamic. The static version contends that an exclusive focus on the sovereign state is not justified until all units of analysis, 
such as supranational organisations, politically autonomous regional governments, and transnational cultural communities, are considered in turn. Although it is not in itself problematic that the statists and the liberal nationalists deem human association within the nation-state to be morally relevant, there might be other equally, if not more fundamentally appropriate units to be chosen (Valentini 2011, pp. 78-85). Hence, with regard to the statist and liberal nationalist accounts of distributive justice, 'selection of the unit of analysis and the distribution of boundaries separating one set of practices from the other has so far remained unjustified' (Ypi 2012, p. 74). The dynamic version of the charge of status quo bias accuses statists and liberal nationalists of wilfully ignoring important facts about the current world order, due to their idealisation of human association within nation-states. This leads to their failing to assist moral agents with practical choices (Valentini 2011, pp. 85-90). Since extreme poverty and radical substantive inequality in material terms at the global level can be traced back to the unfair global economic order, they cannot be effectively tackled without having global institutions in place to coordinate the collective efforts of all nation-states. By letting an idealised account of human association within nation-states trump all other ethical concerns with global threats, including the unfair distribution of material advantages, statists and liberal nationalists do not offer any actionable guidance for resolving the urgent problems faced by all humanity.

I agree with the cosmopolitans that in order to retain the critical elements of distributive principles, one has to distance oneself from the world as it is. Otherwise, the best we can achieve would be an affirmation of the normative understandings which the existing world order inculcates in each of us through socialisation, such that fundamental change would indeed be unattainable. Nevertheless, this still does not serve to defeat the statists and liberal nationalists' methodological commitment to taking account of particular distributive contexts because even though the ideal world order is not based on the actual, as Rawls says, we still have to rely on speculation and conjecture in order to argue for it. According to Miller, a realist utopia implies, 'by extending the limits of political possibility-exploring different ways in which societies might be reordered in the name of greater justice-we shall also come to a better understanding of the limits of the reshaping, and therefore become reconciled to those aspects of our condition that cannot be changed' (Miller 2013, p. 31). Following Miller, Risse argues that a realist utopia can be broken down to three characteristics. First, 'a realistic utopia is relative to time. What is realistically utopian now may differ from what it is generations later'. Second, 'a realistic utopia reconciles us with our social world: some aspects of that world we cannot change, at least now, or we would be ill-advised to change'. Third, although a realistic utopia goes beyond what is feasible to achieve now, it 'must contain principles that members of that society could be brought to accept by reasoned discussion, which means that the principles cannot have implications that those citizens would find abhorrent' (Risse 2012, p. 322). Therefore, some existing features of a particular distributive context should be allowed to constrain our moral reasoning about distributive justice, insofar as they cannot feasibly be changed in the short term. Otherwise, the distributive principles so produced would not be able to motivate people to give material resources to others. 
Although 'realist utopia' is proposed in The Law of Peoples (1999), it makes it possible to adopt both Rawls's original position at the domestic level in A Theory of Justice (1977) and Political Liberalism (1993), and his second position at the international level. The original position is the hypothetical setting within which, behind a 'veil of ignorance', rational individuals with equal standing choose freely among the possible governing principles of justice in order to advance their respective personal interests (Rawls 1999, p. 17). It is established according to a criterion which Rawls calls 'reasonableness'. Reasonableness is associated 'with the willingness to propose and honour fair terms of cooperation, and second, with the willingness to recognise the burdens of judgment and to accept their consequences'. Reasonableness is concerned with the motivation to give, insofar as Rawls associates 'reasonableness' with Scanlon's principle of moral motivation. As he explains,

"Scanlon's principle is more than a psychological principle of motivation (though it is that) since it concerns the fundamental question why anyone should care about morality at all. The principle answers this by saying that we have a basic desire to be able to justify our actions to others on grounds they could not reasonably reject - reasonably, that is, given the desire to find principles that others similarly motivated could not reasonably reject... The two aspects of reasonable as a virtue of persons one may see as two related expressions of this desire" (Rawls 1993, p. 49f).

In other words, by proposing models of citizens and peoples at the first and the second original positions, political theorists could formulate principles of justice that would motivate actual citizens and peoples within liberal societies and at the international level. Therefore, the original position, as a counterfactual thought experiment, attempts through a veil of ignorance to abstract from social contingencies such as social class, ethnicities, and talents while at the same time keeping a sufficient number of features of the particular context in its design, so as to motivate people to accept the distributive implications of particular principles and give resources to others.

That being said, cosmopolitans do recognise the need for distributive principles to motivate people to give. As their second way of justification suggests, cosmopolitans aim to develop distributive principles that people could be brought to accept in the right circumstances. Many cosmopolitans strive to discover various ways to motivate people to support redistributive schemes at the global level. For instance, A. Burcu Bayram recently argued that certain values are conducive to the development of a cosmopolitan consciousness among individual citizens of a nationstate. According to him, people are more likely to see themselves as world citizens when they are influenced by the following moral values: altruism or the concern for others' well-being, the willingness to pursue self-interests in a globalised economic order, and the willingness to learn from diversity. In contrast, obedience to convention and tradition undermines people's cosmopolitan consciousness (Bayram 2015, pp. 425-429). Moreover, to better motivate people to support the cosmopolitan project, Nussbaum suggests that existing traditions and conventions could be changed to accommodate the principles of cosmopolitanism through 'cosmopolitan education'. Starting from a very young age, a cosmopolitan education would serve 
to broaden children's focus of care beyond local attachments, including nationhood, extending it to cover the whole human race (Nussbaum 1996, pp. 3-17). Furthermore, John David Cameron argues that besides long-term education, there are other strategies to motivate citizens of individual nation-states to support cosmopolitan ideals: audience segmentation, values, framing and emotional messaging. First, audience segmentation enables cosmopolitans to tailor their messages to the general public according to the preferences of the group of people they are appealing to. Second, cosmopolitans can use values and framing to, depending on different issues, frame their message purposefully in order to stimulate a favourable emotional reaction from the general public. Third, emotional messaging emphasises the need to adopt more emotionally charged strategies to present the cosmopolitan appeal, for instance, rhetoric and narratives (Cameron 2017, pp. 10-13).

Nevertheless, unlike the statists and liberal nationalists, the cosmopolitans have failed to explain how existing human associations shape people's motivation to give in different distributive contexts and the way in which they will possibly affect the chance of success for the various strategies cosmopolitans proposed to motivate people. When they do discuss the implications of existing human associations, they usually aim to prove a qualitative resemblance between the levels of the global and the nation-state. Cohen and Sabel draw attention to a body of global-level regulatory norms and values that coerce people to obey without giving them the possibility to opt out. In this sense, people acquire involuntary membership of the global economic order in the same way as they come by citizenship of a nation-state (Cohen and Sabel 2006, pp. 147-175, 168). Secondly, Valentini and Hassoun demonstrate that the global economic order, based as it is on neoliberal values, places people under certain legal obligations. This body of norms and values can be seen as a corporate agent similar to the nation state (Valentini 2011, p. 194; Hassoun 2014, pp. 78-82). Thirdly, Armstrong argues that nation-states have already signed treaties and international agreements to share nuclear technology, base missiles, and early warning devices on each other's territory in order to protect their mutual physical security. As he says, 'Property regimes are increasingly being coordinated by international agreements, so that violations of intellectual property rights, for instance, by inhabitants of one state can be punished by the government of another state' (Armstrong 2009, pp. 310-311). These types of cooperation among nation-states have come to resemble the reciprocal relationships within them. Therefore, given the qualitative resemblance between the human associations within and between nation states, people should be as motivated to give to the global poor as the poor within their own nation-state.

Because of the limited scope of this paper, I could not examine the validity of this line of argument. However, even granted that people are motivated to give as much at the global level as within nation-states due to globalisation in a variety of areas, nation states still retain a central role in providing for people's needs within their territories. In this light, cosmopolitans still fail to explain how to utilise existing mechanisms such as democratic institutions and the nation-building process to maintain the said motivation to give at the global level, so as to permit substantive equality among people in material terms. Neglect to do this will not only pass over a powerful source of motivation among people to support a set of egalitarian 
distributive principles at global level, but also expose the cosmopolitan project to the constant risk of xenophobic nationalist tendencies that we observed in European Union in recent years. As immigrant crisis, Euro-zone debt issues, and the COVID19 global pandemic assailed the European continent, the EU member states have seen within their respective borders the rise of several variants of nationalism that reject outsiders, take self-protectionist stance, adopt nativist narratives, push back on globalising trend, and resist any international cooperation, including medical nationalism, economic nationalism, and everyday nationalism. Political scientists have long noticed this causal relation between crisis and the resurgence of nationalism, as many cross-country comparative studies suggest people tend to resort to a sense of a common nationality for self-protection and self-assurance especially in time of crisis (Wang 2021, pp. 20-39). If not understood well and managed carefully, these nationalist tendencies are likely to lead to the erosion of the motivational base for the cosmopolitan project. Fortunately, the said causal linkage between crisis and nationalist tendencies does not seem to be linear; conversely, it proves to be more nuanced than previously realised. More specifically, as in the example of COVID19 global pandemic, analysis of opinion polls results in the USA shows that the fear of death and sickness made people cling more firmly to their ideology rather than making them more nationalistic. In order for the apparently more nationalistic public health policies of the federal government to win popular support, they had been carefully crafted to align with the US people's cultural values in order to avoid being rejected by the latter (Su and Shen 2021, pp. 169-187). This means even in a time of deep crisis such as COVID-19 global pandemic, the nuanced linkage between crisis and nationalism can be utilised by the cosmopolitans to keep their global egalitarian distributive scheme from erosion. Hence, in order to better support and, more fundamentally, safeguard cosmopolitan project, the cosmopolitans first and foremost need to have a better appreciation of statists' and liberal nationalists' accounts of the motivation to give on the bases of, respectively, democratic participation and the nation-building process.

\section{Motivation to Give: Statism Versus Liberal Nationalism}

In Sect. 3, I established that cosmopolitans recognise the need for their distributive principles to motivate people to give at the global level but fail to elaborate how to maintain a sufficient level of motivation through mechanisms such as democratic participation or the nation-building process. In this section, I will discuss the comparative advantage of Miller's theory of nationality vis-à-vis Habermas's notion of constitutional patriotism. Since Habermas's theory captures the important presupposition statists implicitly make in order to ground their distributive principles in the administrative state, demonstrating the insufficiency of Habermas's theory will also serve to call into question the validity of the statists' account of people's motivation to give. Firstly, I compare Miller's theory of nationality and that of Habermas's constitutional patriotism. Secondly, I will show that Habermas's account of people's motivation to give is inadequate, because he fails to explain their motivation to participate in the democratic process in the first place. 
First and foremost, in contrast to the cosmopolitans, the statists and liberal nationalists each have a different account of people's motivation to give within the context of the nation-state. Whereas liberal nationalists explain the said motivation on the basis of a common national identity developed through the nation-building process, statists make implicit appeal to democratic participation as the mechanism that cements a sense of social solidarity.

Miller develops his theory of nationality in On Nationality (1995), Citizenship and National Identity (2000) and Global Justice and National Responsibility (2007). As he argues, "nationality answers one of the most pressing needs of the modern world, namely, how to maintain solidarity among the populations of states that are large and anonymous such that their citizens cannot possibly enjoy the kind of community that relies on kinship or face-to-face interaction' (Miller 2000, pp. 31-32). Possessed of a common national identity, citizens will be sufficiently motivated to solve collective action problems, pursue distributive justice and practice deliberative democracy. First, many of the functions of the state involve citizens' voluntary cooperation, requiring their willingness to give at their own expense. Without a sense of solidarity among individuals, even the minimal state function of presiding over the market economy, whose outcomes depend primarily on individuals pursuing personal interests, would be unworkable, because the ground rules of market transactions require a level of mutual trust among the participants. Second, a sense of a common nationality could ground the special obligations among people because the obligations arise from and are integral to intrinsically valuable human relationships within the national community (Miller 2007, p. 35). In other words, by seeing others as fellow members of a national community, each citizen is sufficiently motivated to support a redistributive scheme at their own expense. Third, citizens require a sense of solidarity so as to be motivated to practice democratic deliberation responsibly in two senses: first, 'the reasons given in political debate should be sincerely held, and not merely adopted as an expedient way of promoting sectional interests'. Second, 'citizens should be willing to moderate their claims in the hope that they can find common ground on which policy decisions can be based' (Miller 1995, p. 96, 97).

In comparison with Miller, the statists' account of the motivation to give resorts to citizens' democratic participation, rather than a feeling of common national identity. As mentioned in Sect. 2, statists such as Nagel, Blake and Sangiovanni advance the three leading accounts of distributive justice grounded in, respectively, involuntary membership granted by the state, legal coercion imposed by the state, and reciprocal relations facilitated by the state. All of these accounts are predicated on the assumption that only the administrative state is morally relevant to the formulation of distributive principles. Nationalist sentiments are not as imperative to the functioning of the state as the liberal nationalists argue. Even though most statists accept the importance of social solidarity among citizens, they contend that this could be realised through citizens' direct or indirect participation in the democratic decision-making process.

A detailed account of the motivation to give is not part of the statists' theory of distributive justice. In this paper, therefore, I will only address one of the leading theories in support of this assumption. This theory, formulated by Jürgen Habermas, inspired a school of thought known as 'constitutional patriotism'. According 
to this theory, social solidarity among citizens could be developed through participation in a deliberative process based on 'communicative action'. A communicative action occurs when 'actors in the roles of speaker and hearer attempt to negotiate interpretations of the situation at hand and to harmonise their respective plans with one another through the unrestrained pursuit of illocutionary goals'. The reverse side of this is termed 'strategic action', that is, when 'language is used only as a medium for transmitting information, (and) action coordination proceeds through the mutual influence that actors exert on each other in a purposive-rational manner' (Habermas 1996, p. 18). Through every successful communicative action, the amount of shared normative understanding among citizens will increase and thereby strengthen their interpersonal relationships.

Habermas's theory of constitutional patriotism seems to explain why nationalist sentiments are not indispensable to the functioning of the administrative state. However, as I will shortly demonstrate, he fails to provide an adequate explanation as to why citizens participate in the communicative action in the first place. In the following, I will reject three possible accounts of the said motivation: (1) the unavoidable presuppositions of communicative action, (2) the coercive power of the legal system and (3) the shared political culture among citizens.

First and foremost, Habermas believes that inherent in the idea of communicative action are certain normative expectations that will effectively regulate the deliberative procedure based on validity claims. These normative expectations are (a) 'all competent speakers be able to participate in the envisaged process of shared deliberation', and (b) 'this right of participation should not be abridged by coercion or compulsion' (McMahon 2011, p. 204). Citizens cannot but presuppose these conditions when they commit to a communicative action.

There are two explanations for this. On the one hand, Habermas could be relying on the conviction that no one participating in a communicative action could consider renouncing its rules. As long as one intends to communicate any meaning at all with another interlocutor and expect them to accept his/her claims, he/she has to already presuppose the rules of communicative action. However, Michael James is correct in contending that this explanation pertains only to 'those actors who have already adopted a reflective level of communicative action without clarifying what motivates actors to engage in reflective communicative action...in the first place' (James 2003, p. 168). It does not consider a scenario wherein individuals refuse to even communicate meaning on the basis of validity claims but instead resort to commands backed by threats and violence.

On the other hand, Habermas argues that the presuppositions of communicative action are universal to all human communication, in the sense that even strategic action is a distorted form of such action. Leaving the institutional guarantee - the category of law-aside for the moment, it is apparent that citizens' decision to engage in communicative rather than strategic action is only coordinated by voluntary consent. Nevertheless, according to Johnson, thus far Habermas insists on supplying an explanation for the coordinating role of consent with the concept of communicative action alone (Johnson 1991, p. 192). This amounts to the assertion that in human communication, all individuals automatically 
orient towards reaching agreement rather than pursuing personal interests, solely because they are cognitively competent for such a task.

However, this attempt to explain individuals' motivation to participate in a communicative action rather than a strategic one is wanting because it gives too little credit to the moral agency of citizens. As it stands, this explanation runs into the same problem as the first one, insofar as there are other ways of interacting available to individuals that do not involve any communication at all. This leads one to question why individuals are motivated to resort to communication at all, even if communicative action is universal to all human communications. Hence, it seems that the presuppositions of communicative action cannot explain citizens' motivation to support a legally institutionalised communicative action at state level, because it is concerned with citizens' cognitive competences rather than their motivation.

The second account of motivation suggests that a coercive legal system could orient the citizens towards a communicative action rather than a strategic one. In other words, the threat of coercive positive law would motivate self-interested citizens to support a legally institutionalised communicative action at state level because of the costs entailed in resisting it. However, Habermas also argues that positive law has a dual character. He says, 'In the legal mode of validity, the facticity of the enforcement of law is intertwined with the legitimacy of a genesis of law that claims to be rational because it guarantees liberty' (Habermas 1996, p. 28). In other words, the ability of positive law to coerce citizens into complying with it is grounded in the possibility that the same citizens are able to discuss and repeal the law through a just deliberative procedure.

In light of its dual character, the legal system faces a dilemma. While being open to reasonable disagreement and revision, some of its foundational principles cannot be open to revision as are other derivative legal rules, insofar as they lay down the institutional framework of the law-making process itself. In this sense, to say that the legal system could legitimately coerce citizens to support a legally institutionalised communicative action at state level is to invite an infinite regress involving the establishment of a society-wide communicative action and the validation of the normative core of the legal system. Thus, between the discursively established validity of the normative core of the legal system and the legally institutionalised communicative action, which comes first? In order to avoid this type of infinite regress, Habermas cannot rely on the coercive legal system to motivate citizens to participate in a society-wide communicative action.

Lastly, Habermas could explain people's motivation on the basis of a shared political culture. In light of the problem with the second account of motivation, Michelman suggests that people would focus their reasonable disagreement on their collective identity, rather than the normative core of the legal system, thereby solving the abovementioned infinite regress, if they share a common political culture (Michelman 2001, pp. 261-269). This normative culture consists of 'the rationally based conviction that unrestrained freedom of communication in the political public sphere, a democratic process for settling conflicts, and the constitutional channelling of power together provide a basis for checking illegitimate power and ensuring that administrative power is used in the equal interest of all' (Habermas 1994, p. 135). Nevertheless, Michelman fails to tell us why these political-cultural convictions are 
valid in the first place. It is doubtful that the populations of liberal countries already share all these normative convictions to the extent as required by Habermas's account. In the case that the shared political culture does not contain all the necessary convictions, the normative core of the legal system would again be exposed to possible revision by the people.

Drawing on Michelman's arguments, Alessandro Ferrara tackles this problem by describing the formation of a shared political culture as an open-ended political project that in time comes to support the normative core of positive law. In other words, rather than picturing the establishment of the legal system as an originary act, we could understand it as a gradual, open-ended development. An accommodating political culture would emerge alongside this historical process, thereby motivating people to support the legal system (Ferrara 2001, p. 787). However, in order for the shared political culture to motivate citizens to support a legally institutionalised communicative action, it has to help citizens comprehend the desirability of the legal system. During the gradual historical process, there must have been times when a new political culture was needed to replace the old one. Given the difference between the old and the new political cultures, it is questionable that Habermas's notion of a shared political culture could help people comprehend the desirability of the new legal system. This is because his notion consists in a set of particular normative convictions specially formulated to support a legal system based on communicative action. People could only be brought to comprehend the desirability of the legal system if, and only if, they already accept these normative convictions. This again leads to the infinite regress described in the second account of motivation.

Thus, Habermas's three explanations of people's motivation to participate in a deliberative process based on a communicative action do not obtain, which undermines the plausibility of the statists' attempt to bypass the need for a shared nationalist sentiment among citizens. It seems that participation in the democratic process alone cannot develop a sufficient level of social solidarity. Therefore, the statists are wrong to exclude nationalist sentiments from their account of the motivation to give, because people require a common national identity in order to be sufficiently motivated to participate in the democratic process in the first place.

\section{Towards a Dynamic Account of the Motivation to Give}

In the last section, I showed that the statists' account of a motivation to give on the basis of people's democratic participation is insufficient, because they require a common national identity to be motivated to participate in democratic deliberation in the first place. ${ }^{1}$ In this section, I will demonstrate that Miller's account of

\footnotetext{
1 I recognise that there are other human sentiments that could be utilised to motivate people to give, such as the ones particular to familial relationships, friendship, religious and community. Nevertheless, I maintain that cosmopolitans should aim to develop a sense of global solidarity similar to the nationalist sentiments for two reasons. First, nationalist sentiments are directed towards a collective identity that is inclusive and malleable and therefore could accommodate various different human allegiances including but not limited to the abovementioned ones. Second, unlike other sentiments, nationalist sentiments could in principle be held accountable to the democratic control of all citizens. Due to the limited scope of this paper, I will not elaborate on these reasons.
} 
the motivation to give lacks a dynamic vision of how to extend it to the global level through the nation-building process. First, I will prove that Miller recognises the need to extend democratic institutions to the global level but deems this unfeasible because of people's lack of sufficient motivation to support such institutional arrangement and give resources to the global poor. Second, I will show that the abovementioned reluctance to extend democratic institutions to the global level is caused by Miller's reliance on Rawls's method of 'reflective equilibrium'. This prevents him from realising that the motivation to give is brought about through people actually deliberating about their common identity. Third, I will suggest that one way to remedy this problem is to endorse a global democratic process that would enable people of all countries to deliberate on a common identity, thereby creating sufficient motivation to give in the long term.

First and foremost, as mentioned in Sect. 2, Miller's justification for the restriction of the regulation of substantive inequality to the level of the nation-state is based on the fact that human association at the global level does not sufficiently resemble the one within nation states. Specifically, it does not (1) confer involuntary membership, (2) impose legal coercion, (3) facilitate reciprocal cooperation, or (4) imply a common identity. Essentially, Miller is arguing that human association needs to possess not only the features of an administrative state, as the statists insist, but also a common identity developed through a purposeful nation-building process. At the same time, he is reluctant to visualise a dynamic process whereby human association at the global level could be reshaped to resemble the one within the nation state. According to Stears, an explanation for this could be Miller's conservative bias towards an existing international system based on sovereign nation-states. As early as in Principles of Social Justice (1999), Miller manifested a clear preference for the nation-state over other possible political arrangements which cosmopolitans propose in light of the increasing pressures of globalisation. As Stears argues,

Miller has gone too far in restricting the political theorist's scope for manoeuvre. For although he is absolutely right to highlight the need for theorists to appreciate both the structural and attitudinal preconditions for social justice, the particular account of those preconditions offered and the prescriptive guidelines for what theorists should do if those preconditions are not met are both unduly pessimistic (Stears 2003, p. 30).

As a result, Miller's account of distributive justice lacks the necessary dynamism to accommodate the changing nature of human association at the global level. Veit Bader is correct to point out,

Miller's focus on the 'nation state' and (traditional state's) 'citizenship' does not explore the opportunities of multi-level polities and multi-level and multilayered citizenship, of trans-national polities such as the EU and trans-national citizenship in particular, which provide promising opportunities to accommodate transnational and global shifts in affiliations, loyalties, identities and obligations. (Bader 2013, p. 175) 
In response to these critiques, Miller is quick to acknowledge the impact of globalisation on human association at the global level. As he admits, 'Perhaps what we are witnessing is the slow emergence of new nationalities such as a European nationality; so that national identities will coexist at different levels' (Miller 1995, pp. 159-60). In other words, due to globalisation, people's affiliations have been reshaped to include supranational, subnational and transnational human associations. All these newly emerging affiliations should be recognised as identities similar to the national identities within traditional nation states. However, the emergence of these new identities does not imply the need for alternative political arrangements, because the latter are not yet strong enough to resemble the national identities within traditional nation states. Consequently, people at these levels of affiliation 'are not involved in relations of reciprocity, whereby I may agree to promote your interest on this occasion on the understanding that you will support mine sometime in the future. Nor are they held together by communal ties or relationships of mutual trust' (Miller 2000, p. 95). Hence, people at these levels do not have the same motivation to give as people within nation states, which precludes any successful establishment of democratic institutions. It follows that in the absence of both democratic institutions and a sufficient level of motivation to give at the global level, the regulation of substantive inequalities in material terms is not relevant globally.

Having said that, Miller's account of the nation-building process describes a dynamic mechanism whereby people originally belonging to different cultural communities could come to develop a shared collective identity at the national level. According to Miller, national identity is a malleable concept that varies from country to country and can only be determined through democratic deliberation among all citizens on an equal footing. As he says, 'what must happen in general is that existing national identities must be stripped of elements that are repugnant to the self-understanding of one or more component groups, while members of these groups must themselves be willing to embrace an inclusive nationality, and in the process to shed elements of their values which are at odds with its principles' (Miller 1995, p. 142). Therefore, Miller's reluctance to endorse the establishment of democratic institutions at the global level could not be explained by the deficiency of his account of the nation-building process, as the process could in principle be replicated at other levels than the nation state.

The problem seems to lie in Miller's understanding of the role of political theorists vis-à-vis laymen in the process of moral reasoning in general, in the sense that he clearly endorses an equal relationship between the two but fails to consider the democratic process which could guarantee it in practice. Miller often professes to have inherited from Rawls the method of individual moral reasoning - the 'reflective equilibrium'. He argues that one has to rely on 'reflective equilibrium' in order to ground his/her normative ideals in reality. As Miller understands 'reflective equilibrium', this starts with a 'considered judgment' that we hold sincerely and independently of our self-interests, and which is gradually transformed by comparison with the prevalent philosophical debates within our society. When, after due consideration, we are convinced that our own 'considered judgments' are coherent with each other and with the prevalent philosophical debates, a 'reflective equilibrium' has been reached. 
Nevertheless, Miller clearly recognises that 'reflective equilibrium' in and by itself is not sufficient in formulating valid political principles, as it is insensitive to the judgments of laymen about morality. As Miller argues, 'the "considered judgments" that form the starting point for this process are the judgments of one particular person; it immediately follows that the "reflective equilibrium" that emerges is also an equilibrium only for the person who has engaged in the thought-process Rawls describes' (Miller 1999, p. 55). Therefore, as Swift observes, Miller requires political theorists to conduct moral reasoning in the hope that the political principles thus produced could be justified to the common people under appropriate conditions (Swift 2003, p. 26). As Miller explicitly says,

A political philosophy that presents itself to any given society as realistically utopian must contain principles that members of that society could be brought to accept by reasoned discussion, which means that the principles cannot have implications that those citizens would find abhorrent. This doesn't mean that the principles must be accepted immediately they are laid out...political philosophy should be in the business of changing political attitudes, of showing people what their convictions mean when applied consistently to political questions. (Miller 2013, p. 37)

In other words, the validity of political principles does not rest on their immediate acceptance by the people and thereby on their strict adherence to people's judgments, as long as they could be somehow justifiable to the people.

In this sense, Miller believes that the validity of political principles hangs on their acceptability to people who have made their own judgments about morality. This means that political theorists and laymen are on an equal footing in formulating political principles on the basis of their own moral judgments while simultaneously taking account of the judgments of others. As Swift observes, Miller finds it unacceptable to defend the absolute authority of professional philosophers over laymen in a contemporary world defined by increasing cultural pluralism. I quote the passage in full:

As Miller says: 'The notion that philosophers can discover truth by means not available to lay persons is even more difficult to defend today than it was in Plato's time'. But that notion has not been defended. The means available to philosophers are also 'available' to laypersons. If there is a difference, it is that philosophers have the time and interest to learn and apply them systematically (Swift 2003, p. 26).

In other words, on the basis of Miller's method, political theorists and laymen are on an equal footing when engaging in moral reasoning about political principles.

I believe this is partly why Miller's account of deliberative democracy requires all people to participate in public deliberation on an equal footing, given that people's different judgements about moral/political issues make it virtually impossible to justify a set of political principles without there being an actual communication among them. As Miller claims, 'all that is necessary in order to embark on political 
dialogue is a willingness to find reasons that can persuade those who initially disagree with us, and one cannot say a priori how abstract those reasons will have to be' (Miller, 2000, p. 55). By agreeing to find the reasons for one's argument, one already recognises the co-deliberators as equal, in the sense that one believes in their ability to arrive at a set of political principles worthy of one's consideration. Moreover, the abstractness of one's argument varies according to the different political issues and the co-deliberators. The reason for this must be that one cannot know for sure what counter arguments the co-deliberators will advance on the basis of their own moral judgments.

Nevertheless, in his account of the nation-building process, Miller neglects to discuss in detail the democratic process whereby people could deliberate about the content of a common national identity. Despite the general requirement for the common national identity to be adapted to people's changing judgments in order to reflect the cultural values of all sections of the society, he fails to explain how democratic deliberation could enable people to reach a consensus on the content of a common national identity which will create enough motivation to give within the nation state. This ambiguity in effect downplays the importance of the democratic institutions in creating a common national identity among people. Moreover, it consolidates the impression that democratic institutions could only be feasibly established among a group of people who already share a common identity and are thereby sufficiently motivated to give. In this sense, Miller's objection to the further institutionalisation of the democratic process at the global level contradicts his own method of developing political principles, because he has no way of knowing whether people have enough motivation to support democratic institutions in the absence of direct communication among them. Similarly, he could not justifiably restrict the regulation of substantive inequalities to nation states, insofar as there is no mechanism for democratic deliberation in place for people to communicate their moral judgments about distributive justice at the global level.

As Miller's account of the nation-building process relies on democratic institutions to facilitate the deliberative process, it could be aligned with the statists' account of the motivation to give. On the one hand, the statists' account, as exemplified by Habermas's 'constitutional patriotism', is based on a more in-depth understanding of the deliberative process involved in developing the motivation to give among citizens. Since according to Habermas, direct communication among people is the mechanism for reaching a consensus on all regulatory norms and values within society, a common national identity could be understood as one of many such norms to be debated among people in a democratic deliberation, as people try to justify their different arguments for the content of a national identity. On the other hand, the statists' account will not render Miller's account of the nation-building process incoherent if we only take it as a better explanation of the democratic process which both Miller and the statists rely on to create the motivation to give. The main difference between Miller and the statists lies in the fact that the latter believe democratic participation per se to be enough for creating the motivation to give among people, whereas Miller resorts to it as a means for developing a common national identity. A particular conception of modern national identity has always been constructed in a specific spatial-temporal context to fulfil certain objectives. A suite of drivers such 
as socio-economic and political forces went into the construction process, as they served to shape the context within which only certain forms could the national identity take and only certain cultural values could it embody. More importantly, political actors such as social elites, academics, and social movements activists clearly contribute to the setting up of these objectives and directly or indirectly lead the construction of national identity in their desired directions so as to harness the motivational force of a common national identity (Mishra 2020, p. 333). Democratic participation enables the various political actors mentioned above to influence the construction of a common national identity reflecting their own understanding within a particular spatial-temporal context, while democratic institutions offer them the necessary institutional framework guaranteeing their equal influence over the outcome of the construction process.

Incorporating the statists' understanding of the democratic process will not only serve to emphasise the role of democratic institutions in creating a common identity among people but also help to formulate a cosmopolitan theory of how to create enough motivation to give at the global level. As the democratic institutions facilitate direct communication among people so as to reach a consensus on a common identity, people could arrive at a better understanding of their shared cultural commonalities. This understanding could in principle help them determine which distributive principles they are sufficiently motivated to support. As no one can predict the result of such a democratic process ex ante, it remains to be seen whether people will be able to develop a common identity that is strong enough to motivate regulating substantive inequalities on the basis of the existing cultural commonalities at the global level. However, the statists' understanding of the democratic process still helps to bring out the dynamic element in Miller's account of the nation-building process, because the democratic deliberation could not only draw upon the existing cultural commonalities but also increase them in the long term. As the global democratic institutions aim to develop a common identity among people, they could also facilitate a deliberation about those common global issues people wish to see addressed through these said institutions. The deliberation about these issues will foster more cultural commonalities among people, thereby building the foundation upon which, in the long term, stronger common identities could be developed globally.

It should be noted that aligning Miller's and Habermas's Accounts of the motivation to give will not collapse the new account into a statist one, in that the potential of developing a common identity among people at global level is predicated on more cultural commonalities among people of different nation-states than Habermas's notion of political culture could possibly encompass. This requisite amount of shared culture will motivate them to engage in a global-level communicative action to deliberate moral/political issues (including distributive justice) and develop a common global identity in the process. Nevertheless, as this shared culture encompasses more norms and values than Habermas's notion of political culture, the new account requires more shared culture than statists' account to kick start the democratic process in question. Having said that, the actual attainment of the shared culture is not essential to the normative validity of the account itself. As far as the dynamic account of the motivation to give is concerned, it is formulated to bridge 
the gap among cosmopolitans', statists', and liberal nationalists' account of global distributive justice at the level of ideal theory in the Rawlsian sense. In other words, it merely contends that under ideal conditions-among them being the requisite number of cultural commonalities - a global-level deliberative democracy should be institutionalised to collectively determine which distributive principles should be adopted among people as well as motivate them to give resource to the needy and the relatively poor. This paper recognises that the requisite number of cultural commonalities, albeit being the critical precondition for a global-level communicative action, should not be presupposed without further empirical study. Under the non-ideal conditions of global politics, this precondition will effectively determine whether and to what extent could the dynamic account of the motivation to give be applied to real-world politics. Further study is needed to evaluate the possibility that the dynamic account of the motivation to give could be realised through a globallevel communicative action among people of different nation-states under the existing conditions of global politics.

\section{Conclusion}

In this paper, I set out to resolve the disagreement over the content of global distributive principles among cosmopolitans, statists, and liberal nationalists. I have shown firstly that all three aim to motivate people to give in support of distributive justice at the global level. Nevertheless, cosmopolitans do not have a positive theory of how to develop enough motivation to give globally. Secondly, the statists' account of the motivation to give is deficient because it fails to recognise the motivational force of a common national identity among people. Thirdly, Miller's account is more plausible than the statists' but fails to facilitate a dynamic process whereby a collective identity could be developed among people at the global level in order to support the cosmopolitan project. It thus needs to be supplemented by the statists' understanding of the democratic process as the mechanism for developing social solidarity among people.

This new account of the motivation to give draws on both statists' and liberal nationalists' insights into the motivational force of human associations within the nation state, thereby offering cosmopolitans a positive theory of how to motivate people to support their distributive principles at the global level. As the development of a common identity among people relies on their participation in the democratic deliberation at the global level, this new account aligns well with the cosmopolitans' endorsement of the further institutionalisation of global citizenship. These theorists have developed different formulations of global citizenship, ranging from world government to the gradual dispersal of authority among multiple levels of governing bodies (Held 2002; Falk 2002; Wendt 2003). Regardless of the various forms of global citizenship, the democratic process engendered therein will aim to develop those distributive principles that people are motivated to support. Simultaneously, it will utilise people's cultural commonalities to develop a stronger common identity, in order to motivate them to give in support of more ambitious cosmopolitan projects in the long term. Thus, whether people will be sufficiently motivated to support 
the regulation of substantive inequalities at the global level remains an open question, cosmopolitans could hope to gradually approximate their ideals through people's democratic participation at this level.

Authors' contributions The author is the sole contributor to this paper.

Funding This work is supported by a grant from Social Science Planning Program of Chongqing. It is part of the research project entitled "An Analysis of US Foreign Policy towards China from Social Constructionist Perspective" (reference number: 2020BS04).

\section{Declarations}

Conflict of interest There is no conflict of interest involved in writing this paper.

\section{References}

Armstrong, Chris. 2009. Coercion, reciprocity, and equality beyond the state. Journal of Social Philosophy. 40 (3): 297-316.

Bader, Veit. 2013. Global justice in complex moral worlds. Dilemmas of contextualised theory. In Nationalism and global justice: David Miller and his critics, ed. H. DeSchutter and R. Tinnevelt. London: Routledge.

Bayram, Burcu. 2015. What drives modern Diogenes? Individual values and cosmopolitan allegiance. European Journal of International Relations. 21 (2): 451-479.

Blake, Michael. 2013. Justice and foreign policy. Oxford: Oxford University Press.

Cameron, John D. 2017. Communicating cosmopolitanism and motivating global citizenship. Political Studies 66 (3): 718-734.

Caney, Simon. 2005. Justice beyond borders: A global political theory. Oxford: Oxford University Press.

Cohen, Joshua, and Charles Sabel. 2006. Extra rempublicam nulla Justitia? Philosophy and Pulblic Affairs 34: 147-175.

Ferrara, Allessandro. 2001. Of boats and principles: Reflections on Habermas's "Constitutional Democracy." Political Theory 29 (6): 782-791.

Falk, Richard. 2002. An emerging matric of citizenship: complex, uneven, and fluid, in Global Citizenship. eds. Dower, N. and Williams, J. Edinburgh: Edinburgh University Press.

Gilabert, Pablo. 2012. From global poverty to global equality: A philosophical exploration. Oxford: Oxford University Press.

$\mathrm{Gu}, \mathrm{Su} .2019$. Nationalism, egalitarianism and global justice. Fudan Journal of the Humanities and Social Sicences 12: 263-273.

Habermas, Jugen. 1996. Between facts and norms. Cambridge: Polity Press.

Hassoun, Nicole. 2014. Globalisation and global justice. Cambridge: Cambridge University Press.

Held, David. 2002. The transformation of political community: rethinking democracy in the context of globalisation. in Global Citizenship. eds. Dower, N. and Williams J. Edinburgh: Edinburgh University Press.

James, Michael R. 2003. Communicative action, strategic action, and inter-group dialogue. European Journal of Political Theory 2 (2): 157-182.

Johnson, James. 1991. Habermas on strategic and communicative action. Political Theory 19 (2): 181-201.

McMahon, Christopher. 2011. Habermas, Rawls and moral impartiality. In Habermas and Rawls: Disputing the political, ed. J. Finlayson and F. Freyenhagen. London: Routledge.

Michelman, Frank. 2001. Morality, identity and "constitutional patriotism." Ratio Juris 14 (3): $253-271$.

Miller, David. 1995. On nationality. Oxford: Oxford University Press.

Miller, David. 1999. Principles of social justice. Cambridge MA: Harvard University Press.

Miller, David. 2000. Citizenship and national identity. Cambridge: Polity Press.

Miller, David. 2007. National responsibility and global justice. Oxford: Oxford University Press. 
Miller, David. 2008. Political philosophy for earthlings. In Political theory: Methods and approaches, ed. D. Leopold and M. Stears. Oxford: Oxford University Press.

Miller, David. 2013. Justice for earthlings: Essays in political philosophy. Cambridge: Cambridge University Press.

Mishra, Manoj Kumar. 2020. Interogating naturalness of national identity. Fudan Journal of the Humanities and Social Sciences 13: 315-335.

Nagel, Thomas. 2005. The problem of global justice. Philosophy \& Public Affairs 33 (2): 113-147.

Nussbaum, Martha. 1996. For love of country: Debating the limits of patriotism. Boston: Beacon Press.

Rawls, John. 1971. A theory of justice. Cambridge MA: Harvard University Press.

Rawls, John. 1993. Political liberalism. New York: Columbia University Press.

Rawls, John. 1999. The law of peoples. Cambridge MA: Harvard University Press.

Risse, Mathias. 2012. On global justice. Princeton: Princeton University Press.

Sangiovanni, Andrea. 2007. Global justice, reciprocity, and the state. Philosophy \& Public Affairs 35 (1): $1-39$.

Stears, Marc. 2003. The political conditions of social justice. In Forms of justice: critical perspectives on David Miller's political philosophy, ed. A.B. Daniel and D.S. Avner. London: Rowman and Littlefield Publishers.

Su, Ruolin, and Wensong Shen. 2021. Is nationalism rising in times of the COVID-19 pandemic? Individual-level evidence from the United States. Journal of Chinese Political Science 26: 169-187.

Swift, Adam. 2003. Social justice: Why does it matter what the people think? In Forms of justice: critical perspectives on David Miller's political philosophy, ed. A.B. Daniel and D.S. Avner. London: Rowman and Littlefield Publishers.

Tan, Kok-Chor. 2019. Global justice, luck, and human needs: Reflections on Gu and Liu. Fudan Journal of the Humanities and Social Sciences 12: 255-261.

Valentini, Laura. 2011. Justice in a globalised world. Oxford: Oxford University Press.

Walzer, Michael. 1994. Thick and thin: Moral argument at home and abroad. Notre Dame: University of Notre Dame Press.

Wang, Zhongyuan. 2021. From crisis to nationalism? The conditioned effects of the COVID-19 crisis on neo-nationalism in Europe. Chinese Political Science Review 6: 20-39.

Wendt, Alexander. 2003. Why a world state is inevitable? European Journal of International Relations. 9 (4): 491-542.

Ypi, Lea. 2012. Global justice \& avant-garde political agency. Oxford: Oxford University Press.

Siyang Liu Doctor of Philosophy in Government and International Affairs,Master of Art in Research Methods of International Relations, Bachelor of Science in Politics and International Relations; Lecturer of International Politics, School of Politics and Public Administration, Southwest University of Political Science and Law; Main areas of research: Belt and Road Initiative, Contemporary China's Borderland Governance, US Foreign Policy Analysis, Global Distributive Justice. 